\section{$\underset{\substack{\text { hommes } \\ \text { \& migrations }}}{ }$}

\section{Hommes \& migrations}

Revue française de référence sur les dynamiques

migratoires

\section{6-1287 | 2010}

Les migrations subsahariennes

\title{
Jean Pierre Liégeois, Roms et Tsiganes
}

Paris, La Découverte, 2009, 125 pages, 9,50 euros

\section{Mustapha Harzoune}

\section{(2) OpenEdition \\ 1 Journals}

\section{Édition électronique}

URL : http://journals.openedition.org/hommesmigrations/1696

DOI : 10.4000/hommesmigrations.1696

ISSN : 2262-3353

\section{Éditeur}

Musée national de l'histoire de l'immigration

\section{Édition imprimée}

Date de publication : 1 juillet 2010

Pagination : 312-313

ISSN : 1142-852X

\section{Référence électronique}

Mustapha Harzoune, « Jean Pierre Liégeois, Roms et Tsiganes », Hommes \& migrations [En ligne],

1286-1287 | 2010, mis en ligne le 29 mai 2013, consulté le 22 septembre 2020. URL : http:// journals.openedition.org/hommesmigrations/1696; DOI : https://doi.org/10.4000/

hommesmigrations. 1696

Ce document a été généré automatiquement le 22 septembre 2020.

Tous droits réservés 


\title{
Jean Pierre Liégeois, Roms et Tsiganes
}

\author{
Paris, La Découverte, 2009, 125 pages, 9,50 euros
}

\author{
Mustapha Harzoune
}

\section{RÉFÉRENCE}

Jean Pierre Liégeois, Roms et Tsiganes, Paris, La Découverte, 2009, 125 pages, 9,50 euros

1 Voilà un petit livre bien utile pour dépasser les gros titres de la presse et les gros mots des responsables politiques, pour aussi mesurer le poids des préjugés qui traînent dans la tête de chacun. Jean-Pierre Liégeois est un spécialiste, auteur de dizaines de livres, rapports, conférences et autres articles sur le sujet. Fondateur en 1979 du Centre de recherches tsiganes de l'université Paris-Descartes, qu'il a dirigé jusqu'en 2003. C'est dire s'il est à son affaire ici. Le souci de l'exhaustivité bute sur les rigueurs de la collection : en une centaine de pages, le lecteur est gratifié d'une somme d'informations indispensables pour trouver son chemin dans le dédale d'un sujet aux ramifications multiples. Pourtant, il aurait peut-être accepté d'échanger quelques éclairages généraux et perspectives historiques pour saisir ce qui fait le quotidien de ces Roms et Tsiganes, objets aujourd'hui de toutes les attentions, bonnes ou mauvaises. Ce n'est là qu'un léger bémol à propos d'un livre dont les atouts sont nombreux, et pas seulement parce que les Roms sont au cœur de l'actualité française et européenne depuis bientôt une vingtaine d'années.

2 Jean-Pierre Liégeois remonte loin, en Inde, pour retrouver la trace de ces communautés dont les premières familles apparaissent en Europe au XIV ${ }^{\mathrm{e}}$ siècle. Roms, Tsiganes, Gitans, Gypsis, Gens du Voyage, Bohémiens, Manouches... les appellations varient pour désigner des groupes qui, pour avoir des origines communes, n'en constituent pas moins des communautés diverses, différentes, appartenant à une "mosaïque", un “ kaléidoscope" où les parties, solidaires en tant que membres d'un tout, n'en affirment pas moins pour autant leur spécificité. Aujourd'hui le terme "rom", de plus en plus souvent employé, marque l'émergence sur la scène politique de ces groupes diversifiés. Si le mot ne recouvre pas l'ensemble des groupes, les Roms d'Europe de l'Est et 
d'Europe centrale sont majoritaires. Intérêt politique, intérêt démographique, l'autre critère permettant d'expliquer cet engouement tient au fait que "rom" est une dénomination de l'intérieur (endomynie) à la différence des autres désignations, souvent chargées en préjugés, données de l'extérieur (exomynie).

3 Avec des estimations variant de 8 à 12 millions, les Roms forment aujourd'hui la plus importante minorité d'Europe. On en compterait entre 1,8 million et 2,4 millions en Roumanie, entre 1 et 2,5 millions en Turquie et entre 450000 et 900000 en Russie. En France, on estime cette population comprise entre 300000 et 400000 personnes.

Jean-Pierre Liégeois s'efforce de dégager les spécificités culturelles tsiganes du folklore et de l'exotisme dans lesquels, non sans ambiguïtés, on voudrait les maintenir. Quant aux approches paternalistes ou technocratiques, elles tendent, elles, à gommer la culture des Roms pour réduire leur mode de vie à un problème social ou une déviance. Langue, organisation sociale, système de valeurs, règles de solidarité... sur tous ces points, l'auteur s'applique à fournir quelques repères. De ce point de vue, la mobilité n'est pas nécessairement consubstantielle à la culture rom: elle est une forme d'adaptation car "ce sont les persécutions dont les Tsiganes sont l'objet qui les amènent à fuir". Les exemples ne manquent pas et, pour en rester au XXe siècle, Jean-Pierre Liégeois revient sur la politique d'extermination menée par les nazis, les politiques de "purification ethnique" en ex-Yougoslavie ou les politiques d'exclusion globale et planifiée en cours... Des raisons sociales et économiques peuvent aussi présider à cette mobilité qui permet alors de travailler, de rencontrer d'autres groupes, d'établir des liens (mariages, échanges, informations...), d'entretenir aussi sa spécificité par rapport aux groupes croisés. "Si le nomadisme n'est ni le produit ni le producteur de la culture tsigane, il apparaît que les deux sont liés, notamment parce que les communautés tsiganes, par choix ou par obligations, ont toujours dû prendre en compte la mobilité dans leur style de vie."

5 Les Roms sont les minorités les plus discriminées d'Europe. Réduire, comme on le fait souvent en France, la question rom à un problème migratoire c'est omettre ces discriminations voire les violences dont ils sont victimes dans les pays de départ (en Roumanie notamment). Les Roms, comme citoyens européens, ont le droit de circuler à l'intérieur de l'espace Schengen. Ils le font. Mais comme ils ne disposent pas du droit à l'emploi, ils sont, comme en France ou en Italie, renvoyés chez eux, manu militari ou avec leur consentement. Renvoyés parfois au casse-pipe. Les mêmes causes produisant les mêmes effets, ces expulsés sauront emprunter les routes qui les ont conduits en France ou ailleurs. Pourtant, la lutte contre les discriminations et pour le respect des droits des minorités roms constitue un des critères à respecter pour les pays candidats à l'adhésion à l'Union européenne. Une condition que l'on s'arrange pour remplir avant d'entrer et avec laquelle on prend des libertés une fois la porte refermée derrière soi...

6 Autre ambiguïté que dénonce Jean-Pierre Liégeois : les politiques menées vis-à-vis des Roms. Après les phases d'"expulsion", de "reclusion", d" "inclusion", pour Jean-Pierre Liégeois nous serions entrés depuis quelques années dans une phase d'“indécision". Ce moment d'incertitude n'est en rien le prélude à une "innovation" en matière de politique : qu'il s'agisse de la prise en compte des caractéristiques culturelles des Roms, de la question de leur citoyenneté ou de l'accès à l'éducation, rien ne permet d'entrevoir des innovations contribuant à lutter contre les discriminations et ce, malgré les recommandations de nombres d'organismes et associations européens. Les derniers événements pourraient même laisser à penser qu'une "réactivation du rejet" des 
Roms et autres gens du voyages se profile, réduisant à zéro toutes les avancées observées ces dernières années.

7 Pourtant, au cœur de ce formidable projet de construction d'un espace européen, ouvert aux différences, aux minorités et aux mobilités, les Roms seraient porteurs d'un savoir et d'une expérience uniques. Et la moindre n'est sans doute pas le fait que pour l'auteur, "l'analyse de la société tsigane est une analyse de la permanence à travers l'éphémère ". Renversant les perspectives, Jean-Pierre Liégeois avance que dans "le mouvement de circulation mondiale" les Roms, "mobiles et minoritaires", auraient une "longueur d'avance" qui pourrait profiter à tous. Une façon de décentrer le regard et d'aérer quelques esprits encrassés par des préjugés identitaires d'un autre temps. Il faut le souhaiter. 